\title{
Percepções de sujeitos de uma escola pública de Ensino Fundamental do Distrito Federal sobre a alimentação escolar e a educação nutricional como tema curricular transversal
}

\section{Perceptions of subjects in a public elementary school of the Federal District about feeding and nutrition education as a cross-curricular theme}

\author{
Daise Ellen de Melo Barbosa ${ }^{1}$, Andréia Araújo Lima Torres²
}

\begin{abstract}
${ }^{1}$ Nutricionista, Pós-Graduanda do curso Educação e Promoção da Saúde NESPROM/UNB. Brasília - DF.

${ }^{2}$ Nutricionista, Mestre em Nutrição Humana, Professora do Departamento de Nutrição da Faculdade JK, Brasília - DF.
\end{abstract}

\section{RESUMO}

A promoção da saúde no contexto escolar tem sido amplamente recomendada por inúmeros órgãos internacionais. $\mathrm{E}$ um dos aspectos essenciais da promoção da saúde é a alimentação. Sabe-se que as práticas alimentares saudáveis iniciam-se na infância e a escola exerce um papel protagonista nesse processo. O Programa Nacional de Alimentação Escolar tem entre outras finalidades a de promover a formação de hábitos alimentares saudáveis. Legislação brasileira recente incluiu a educação alimentar e nutricional no currículo escolar. Assim, este trabalho objetivou conhecer as opiniões, as atitudes, assim como as representações de atores escolares sobre alimentação e sobre a educação nutricional no contexto escolar. Trata-se de um estudo transversal, qualitativo, realizado em uma escola pública de Ensino Fundamental do Distrito Federal. Os dados foram coletados por meio da entrevista estruturada e da observação participativa, analisados por meio do método de análise de conteúdo e reunidos em 4 tópicos: (a) Escola promotora de Saúde; (b) A merenda escolar e sua importância; (c) Alimentação saudável e consumo de frutas e verduras; e (d) Educação nutricional. Verifica-se que apesar dos sujeitos possuírem conhecimentos sobre a importância e o objetivo da alimentação saudável e do lanche escolar, não acreditam que sejam modelos para os alunos e não aliam a teoria que possuem à sua prática de vida diária. A idéia que fazem acerca da educação nutricional ainda é incipiente. A constituição de grupos de trabalhos multidisciplinares pode facilitar a efetivação da proposta da Escola Promotora da Saúde e ser um real aliado para concretização dos princípios do Sistema de Saúde.

Palavras-Chave: Educação nutricional, Alimentação saudável, Merenda escolar, Promoção da Saúde.

\section{ABSTRACT}

Health promotion in the school context has been widely recommended by many international bodies. And one of the essential aspects of health promotion is the 
feeding. It is known that healthy eating habits begin in childhood and the school plays a leading role in this process. The National Schooler Feeding Program has among other purposes to promote the formation of healthy eating habits. Brazilian legislation included recently alimentary and nutrition education into school curriculum. Thus, this study aimed to determine the opinions, attitudes, and representations of the schoolers actors about feeding and nutritional education in the school context. This is a crosssectional, qualitative study realized in a public elementary school of the Federal District. The data were collected through structured interviews and participative observation, analyzed by the method of content analysis and assembled on 4 topics: (a) health promoting school; (b) The school meal and its importance; (c) Healthy eating and consumption of fruits and vegetables; and (d) Nutrition education. We verified that despite the subjects have knowledge about the importance and the goal of healthy feeding and school meal, they do not believe that they are models for students and they do not combine the theory that they have with their daily practice life. The idea they have about the nutrition education is still incipient. The creation of multidisciplinary workgroups can facilitate the realization of the proposal of the Health Promoting School and be a real ally to achieve the principles of the Health.

Keywords: Nutrition education, healthy feeding, School meal, Health Promotion.

\section{INTRODUÇÃO}

Um dos aspectos essenciais na promoção da saúde quando se fala em cuidados da criança é a alimentação (ROTENBERG; DE VARGAS, 2004). Infelizmente estudos epidemiológicos apontam uma piora dos padrões alimentares do brasileiro, o que contribui para a piora da qualidade de vida. Evidências epidemiológicas apontam a necessidade da população aumentar o consumo de frutas e verduras como forma preventiva reduzindo-se os riscos de muitas doenças crônicas (ANGELIS, 2001). Como as práticas alimentares saudáveis iniciam-se na infância, existe uma concordância quanto à necessidade de a escola assumir um papel de protagonista nesse processo (GONÇALVES et. al., 2008).

A escola exerce uma influência cada vez maior na alimentação de seus alunos. E considerando-se que é nesta instituição que a criança passa o seu maior tempo, acredita-se que ela possa desenvolver projetos que estejam voltados à educação alimentar. Embora o tema alimentação/nutrição esteja integrado aos currículos escolares, nem sempre as escolas têm trabalhado tal temática. Atualmente tem-se acreditado que os hábitos alimentares podem se diversificar dependendo do que a escola forneça como cardápio diário à criança. Sendo assim, devem ser ofertados alimentos, que possibilitem aos alunos a efetivação positiva de hábitos alimentares saudáveis (FRIZON, 2008).

\subsection{PRÁTICAS ALIMENTARES SAUDÁVEIS}

A promoção de práticas alimentares saudáveis cada vez mais tem sido apontada como uma estratégia de promoção da saúde. Simultaneamente, destaca-se a educação alimentar e nutricional como estratégia para o enfrentamento dos desafios no campo da saúde, alimentação e nutrição, auxiliando na produção de informações 
que contribuem para a tomada de decisões dos indivíduos (SANTOS, 2005). No Brasil a iniciativa de fornecimento da merenda escolar data da década de 30 . Porém, foi somente nos anos 50 que criou-se o Programa Nacional de Alimentação do Escolar (STEFANINI, 1997).

A promoção da saúde no contexto escolar tem sido amplamente recomendada por inúmeros órgãos internacionais (BIZZO; LEDER, 2005). A escola funciona como uma fonte socializadora de impacto na vida das pessoas (GUIMARÃES; BORUCHOVITCH, 2004). A escola deve, assim, cumprir o seu papel social na promoção da qualidade de vida, educando seus sujeitos de forma a efetivar um processo de alimentação saudável (FRIZON, 2008). O Programa Nacional de Alimentação do Escolar (PNAE) tem a finalidade de contribuir para o crescimento, o desenvolvimento, a aprendizagem e o rendimento escolar dos estudantes; atender as necessidades nutricionais dos alunos durante a sua permanência em sala de aula, assim como promover a formação de hábitos alimentares saudáveis (FNDE, 2009). A merenda escolar visa, então, a fornecer algo mais do que a criança recebe em casa (STEFANINI, 1997). Uma das leis brasileiras mais recentes, a Lei $n^{\circ} 11.947$ de 16 de junho de 2009, que dispõe sobre o atendimento da alimentação escolar aos alunos de Educação Básica, inclui a educação alimentar e nutricional no currículo escolar. A referida lei ainda destaca o papel do Programa Nacional de Alimentação Escolar ao contribuir para o crescimento e desenvolvimento biopsicossocial, a aprendizagem, o rendimento escolar e a formação de hábitos alimentares saudáveis dos alunos mediante ações de educação alimentar e nutricional e da oferta de refeições que cubram as suas necessidades nutricionais. Um dos maiores ganhos e que também veio contribuir para a efetivação da promoção da saúde na escola foi a edição da resolução $n^{\circ} 38$ de 16 de julho de 2009, que regulamenta a citada lei. Esta norma ressalta a necessidade da adoção de estratégias de educação alimentar e nutricional como forma de assegurar uma refeição saudável. Entre essas estratégias estão a implantação e manutenção de hortas escolares, a inserção do tema alimentação no currículo escolar, a realização de oficinas culinárias experimentais, entre outras.

Diante da pobreza de boa parte da população brasileira, cresce o número de crianças que vão à escola em jejum e/ou que se alimentam em casa de forma inadequada, sendo a merenda escolar a única refeição do dia para muitas crianças (CAMARGO; ROVINA; NOGUEIRA, 2009). A lei federal no 8913/94, que regulamentou o PNAE e normatizou o repasse dos recursos do programa, estabeleceu a exigência da constituição dos Conselhos de Alimentação Escolar (CAE). O CAE além de exercer papel fiscalizador e controlador dos recursos destinados à merenda interfere nas decisões de compras de produtos e na composição dos cardápios (PIPITONE et. al., 2003). O cardápio deve ser elaborado por nutricionista habilitado e deve suprir $20 \%$ das necessidades nutricionais diárias dos alunos beneficiados e matriculados na educação básica em período parcial, sendo que, quando for oferecida duas ou mais refeições deverão suprir $30 \%$ das necessidades nutricionais e sempre respeitando os hábitos alimentares locais e a vocação agrícola da Comunidade (RESOLUÇÃO No 38/CD/FNDE, 2009). De acordo, ainda, com a referida resolução o cardápio deverá ser diferenciado para cada faixa etária dos alunos e para os que necessitam de atenção específica e, além disto, os cardápios também deverão oferecer pelo menos três 
porções de frutas e hortaliças por semana o que corresponde a $200 \mathrm{~g} / \mathrm{aluno} / \mathrm{semana}$. A citada norma também veda a aquisição de bebidas de baixo teor nutricional como refrigerantes e refrescos artificiais. No Distrito Federal o PNAE é complementado com recursos próprios, sendo a secretaria de educação a responsável por atender a todos os alunos da Educação Infantil e do Ensino Fundamental da Rede Pública de Ensino. Em 2008, 384.594 alunos foram beneficiados com o programa (SEE/DF, 2009).

Os Parâmetros Curriculares Nacionais constituem o plano referencial para a educação no Ensino Fundamental (PCN, 1997). Possuem caráter flexível, integrado e inovador. Além dos componentes curriculares tradicionais, apresentam seis temas transversais: ética, saúde, meio ambiente, pluralidade cultural, orientação sexual e trabalho e consumo (BIZZO; LEDER, 2005). A educação nutricional deve fazer parte deste processo de ensino-aprendizagem, pois contribui para a construção de um conhecimento de modo participativo e integrado entre equipe de saúde, criança e família e escola, aproveitando-se do momento em que as práticas, crenças, saberes e vivências das crianças estão sendo modeladas (BIZZO; LEDER, 2005). A educação nutricional pode ser entendida como sendo uma série de experiências planejadas, facilitando a adoção voluntária de hábitos alimentares ou de um comportamento qualquer relacionado com a alimentação que leve à saúde e ao bem-estar (FAGIOLI; NASSER, 2006). Sendo assim, programas de educação nutricional capacitam crianças para fazerem escolhas corretas (DAVANÇO; TADDEI; GAGLIANONE, 2004). Nesta fase há uma socialização e independência maior, favorecendo uma melhor aceitação de preparações alimentares diferentes (FAGIOLI; NASSER, 2006). Ao considerar o tempo que a criança passa na escola, observa-se que a instituição escolar exerce uma influência cada vez mais abrangente na alimentação de seus estudantes (FRIZON, 2008). É também de extrema importância estimular o consumo de alimentos saudáveis no âmbito escolar e o professor, neste contexto, apresenta papel relevante na aceitação destes alimentos (BIZZO; LEDER, 2005). O professor, neste processo, se torna um dos membros da equipe de saúde escolar, uma vez que além de ter um maior contato com os alunos, envolve-se na realidade cultural e social, possuindo uma comunicação semelhante e mais acessível ao aluno (DAVANÇO; TADDEI; GAGLIANONE, 2004). Sendo assim, a escola desempenha uma função importante na construção de hábitos alimentares saudáveis, pois participa de forma ativa na vida dos alunos e alcança parte da população, contribuindo com a educação para uma vida saudável (FRIZON, 2008).

\subsection{PERFIL NUTRICIONAL DE CRIANÇAS E ADOLESCENTES BRASILEIROS}

No Brasil, tem-se verificado nas últimas décadas um processo de transição nutricional, havendo uma redução da prevalência da desnutrição infantil, constatado entre os anos de 1974/75 e 1989. Estudos de prevalência com amostras representativas tanto do Brasil quanto de suas cinco macrorregiões apontaram que nos últimos trinta anos, a prevalência de desnutrição em crianças declinou em cerca de 80\% (KAC; SICHIERI; GIGANTE, p. 450, 2007). Analisando-se os dados da Pesquisa Nacional sobre Saúde e Nutrição (PNSN-1989), encontrou-se uma prevalência de $7,6 \%$ de sobrepeso em adolescentes. E ao se comparar os dados do 
Estudo Nacional da Despesa Familiar (ENDEF), de 1974/75 com os dados da Pesquisa sobre Padrões de Vida, de 1996/97, achou-se um aumento na prevalência de sobrepeso e obesidade de 4,1\% para 13,9\% em crianças e adolescentes de 6 a 18 anos. Importante apontar que estudos realizados em algumas cidades do Brasil ressaltam que o sobrepeso e a obesidade já atingem $30 \%$ ou mais das crianças e adolescentes. Diversos fatores contribuem na gênese da obesidade como os genéticos, os fisiológicos e os metabólicos, no entanto são os fatores relacionados com às mudanças no estilo de vida e aos hábitos alimentares que explicam melhor 0 aumento na prevalência da obesidade (OLIVEIRA; FISBERG, 2003).

\subsection{COMPORTAMENTO ALIMENTAR E A IMPORTÂNCIA DA ALIMENTAÇÃO}

Trabalhos sobre nutrição infantil têm evidenciado que o comportamento alimentar infantil é determinado primeiramente pela família e secundariamente pelas outras interações psicossociais e culturais da criança. Sendo que a neofobia alimentar pode ser diminuída através de métodos de aprendizagem na alimentação, permitindo que a criança aprenda sobre saciedade, fome, sabores dos alimentos, quantidade de alimentos que deve ser consumida (RAMOS; STEIN, 2000). O perfil dietético de crianças, determinado primeiramente pela família, sofre forte influência da televisão. Os comerciais sobre alimentos apresentam efeitos imediatos sobre as preferências infantis (KAC; SICHIERI; GIGANTE, p. 351, 2007). A importância da alimentação saudável, principalmente para organismos jovens, em fase de desenvolvimento como forma de prevenir e controlar doenças crônicas é fato incontestável (BOOG, 1999). A alimentação para a criança em idade escolar é de grande importância, residindo no fato de ser esta uma fase de crescimento lento, porém, constante. Diversos fatores podem afetar o estado nutricional do escolar como: ingestões inadequadas, doenças nutricionais, fatores psicossociais, pobreza, modo de vida, entre outros (FLÁVIO; BARCELOS; LIMA, 2002). Crianças em idade escolar necessitam de alimentos em uma determinada quantidade, possibilitando o alcance do pleno potencial genético de crescimento e desenvolvimento. Sendo assim, a "Estratégia Global da Organização Mundial de Saúde - OMS" preconiza uma redução do consumo de alimentos com alta quantidade de gordura, sódio e açúcar, aumentado o consumo de frutas, legumes e verduras. Na adolescência as alterações biológicas, psicológicas, cognitivas e sociais interferem no comportamento alimentar. Fatores como: atitude dos pais e amigos; normas, valores culturais e sociais; a mídia; o boom dos fast-food; o conhecimento de nutrição e manias alimentares; as necessidades e características psicológicas; a imagem corporal; os valores e experiências pessoais; a auto-estima; as preferências alimentares; a saúde e desenvolvimento psicológico são variáveis que afetam e possuem uma inter-relação com o comportamento alimentar nesta fase da vida (FAGIOLI; NASSER, 2006).

Em face da importância da estratégia de promoção da saúde discutida mundialmente a qual aponta a necessidade do cultivo de hábitos alimentares saudáveis, de preferência desde a infância, como uma das formas de se alcançar qualidade de vida e tendo-se em vista o amparo legal recebido no Brasil acerca do tema alimentação escolar e educação nutricional, a escola se torna uma das responsáveis em auxiliar neste processo educativo. Diante disto, torna-se 
imprescindível o estudo das percepções de educadores e de outros atores sobre a alimentação escolar e a educação nutricional como tema curricular transversal a ser trabalhado, auxiliando na identificação dos possíveis problemas vivenciados diariamente pelos atores sociais escolares em relação a esta temática. Assim, este trabalho tem com objetivo principal conhecer as opiniões, as atitudes, assim como as representações de atores escolares sobre alimentação e sobre a educação nutricional no contexto escolar.

\section{METODOLOGIA}

Foi realizado um estudo transversal, com duração de 15 dias, onde empregouse o método qualitativo, objetivando o entendimento, a interpretação das opiniões, atitudes e representações dos sujeitos estudados. A abordagem qualitativa tem a finalidade de entender fenômenos sob a perspectiva dos participantes (FRANCO; BOOG, 2007).

As técnicas utilizadas para a coleta de dados foram a entrevista estruturada individual e coletiva (ANEXO I) e a observação participativa. A entrevista individual foi realizada com as merendeiras e a entrevista coletiva com os professores e a coordenadora pedagógica, em virtude da disponibilidade da escola. A entrevista é usada a fim de se obter informações dos sujeitos sobre seus saberes, crenças, sensações, pretensões, assim como suas explicações e opiniões sobre algo (FRANCO; BOOG, 2007). As entrevistas foram realizadas pela própria pesquisadora. A observação participativa consistiu na anotação de aspectos referentes ao preparo, distribuição e consumo da merenda e atitudes e práticas dos sujeitos durante a alimentação (lanche escolar), com o objetivo de entender o comportamento destes atores durante a permanência na escola.

Buscou-se, também, informações adicionais referentes ao Programa Nacional de Alimentação do Escolar no Núcleo de Assistência do Educando da Diretoria Regional de Taguatinga.

O presente trabalho foi aprovado pelo comitê de ética em pesquisa (FR 289056 E 101-2009). Todos os participantes assinaram um termo de consentimento livre e esclarecido (ANEXO II).

\subsection{LOCAL DE PESQUISA}

A pesquisa foi realizada em uma escola de ensino fundamental, da rede pública localizada na região administrativa de Taguatinga - DF.

A Região Administrativa III - Taguatinga está localizada a oeste de Brasília com cerca de 259.123 habitantes. Taguatinga possui 04 Centros de Educação Infantil, 13 Centros de Ensino Fundamental, 04 Centros de Ensino Médio, 33 Escolas Classes, sendo 04 Rurais, 05 Centros Educacionais, 01 Centro de Ensino Especial, 01 CAIC, 01 Escola Técnica, 04 Conveniadas, 01 Centro Interescolar de Línguas - CILT. Estão matriculados na Escola Pública de Taguatinga, 57.116 alunos, sendo que, 4.161 são alunos das Escolas Conveniadas (DF/GOV, 2009). 


\subsection{SUJEITOS}

A pesquisa foi realizada com a coordenadora pedagógica e professores do Ensino Fundamental e com merendeiras da escola, que concordaram em participar da pesquisa. Interessaram-se em participar da pesquisa 11 sujeitos o que corresponde a $55 \%$ do total da amostra, sendo 9 do sexo feminino (1 coordenadora pedagógica, 5 professoras e 3 merendeiras) e 2 do sexo masculino (2 professores). A amostra obtida foi composta por 4 professores de anos iniciais e 3 professores de anos finais. As entrevistas foram realizadas na escola no período de coordenação dos professores e nos momentos de intervalo.

\subsection{CRITÉRIOS DE INCLUSÃO}

Ser professor, Coordenador pedagógico de Ensino Fundamental ou merendeira da escola e preencher o termo de consentimento livre e esclarecido.

\section{RESULTADOS E DISCUSSÃO}

Os dados das entrevistas foram analisados através do método de Análise de conteúdo e interpretação. A análise de conteúdo é mais do que um simples procedimento, busca-se a teoria e a prática no campo das investigações sociais (MINAYO, 2000 apud VOORPOSTEL, 2007).

\subsection{ESCOLA PROMOTORA DE SAÚDE}

Este tópico tem como objetivo apresentar as idéias dos sujeitos em relação a sua escola atuando na promoção da saúde, assim como demonstrar se a escola tem contribuído ou não para a concretização do ideário promocionista. De acordo com a Organização Pan-americana de Saúde a promoção da saúde na escola deve partir de uma visão multidisciplinar e integral, onde as pessoas são consideradas em seu contexto comunitário, social, ambiental e familiar. Deste modo, as práticas de promoção da saúde devem ter a finalidade de desenvolver conhecimentos, habilidades, reflexões em torno, por exemplo, do auto-cuidado da saúde e prevenção de comportamento de risco (GONÇALVES et. al., 2008).

Ao ser questionado qual o papel da escola no auxílio à formação de hábitos alimentares saudáveis, a maioria dos atores escolares $(N=10 ; 90,9 \%)$ citou a importância de se educar e de se conscientizar os alunos para serem capazes de aderirem a uma alimentação saudável e balanceada. Apontaram, ainda, que a alimentação saudável seria um requisito importante para se ter uma vida longa e feliz.

Apenas um sujeito ( $N=1 ; 9,09 \%$ ), no entanto, disse não observar nenhum papel da escola na formação de hábitos alimentares. Deve-se lembrar que a alimentação saudável é uma das concepções e estratégias da promoção da saúde (SANTOS, 2005).

Perguntou-se, também, nesta categoria se os sujeitos consideram a sua escola promotora de saúde e em caso afirmativo quais são as ações que estão sendo realizadas. Dos que se manifestaram, 45,4\% $(N=5)$ afirmaram que sua escola 
promove a saúde através de projetos trabalhados em sala de aula, principalmente na disciplina de ciências. Ressaltaram o programa "Dentista na Escola". No entanto, outros 36,3\% ( $\mathrm{N}=4)$ afirmaram que sua escola não atua na promoção da saúde, por falta de estrutura e projetos que a escola não possui. Cabe ressaltar que a Comissão de Especialistas em Educação em Saúde da Organização Mundial de Saúde, em 1954, ressaltou a necessidade de se realizar, no âmbito escolar, várias ações e atividades que auxiliassem a promoção da saúde, não se restringindo somente a transmissão de conhecimentos sobre saúde. Foi, então, neste sentido introduzido o conceito de Escola Promotora de Saúde (GONÇALVES et. al., 2008).

Pode-se observar que a escola peca por não ter um projeto próprio que invista em ações de promoção da saúde, uma vez que após a IV Conferência de Jacarta foi elaborado um documento intitulado de Declaração das Escolas Promotoras de Saúde, que preconiza que toda a criança tem direito de ser educada em uma Escola Promotora de Saúde, além dos Parâmetros Curriculares Nacionais sugerirem a incorporação dos princípios da promoção da saúde (GONÇALVES et. al., 2008). O programa citado, Dentista na Escola, é uma ação do governo e deverá ser implantado em toda a rede de ensino público do Distrito Federal. Notou-se, ainda, que poucos se preocupam realmente em trabalhar este conteúdo em sala. Poucos sujeitos possuem a concepção de que a escola é o ambiente ideal para se desenvolver programas de promoção e educação em saúde (GONÇALVES, et. al., 2008). A maioria alega a falta de tempo para abordar todo o conteúdo de sua disciplina e ainda realizar outras atividades extras.

\subsection{A MERENDA ESCOLAR E SUA IMPORTÂNCIA}

Esta categoria visa a demonstrar a percepção dos sujeitos sobre a qualidade do lanche escolar e sua importância no dia-a-dia dos alunos e dos demais funcionários.

Ao se abordar a respeito da qualidade da merenda escolar oferecida, a maioria $(\mathrm{N}=9 ; 81,8 \%)$ afirmou ser o lanche muito monótono, variando pouco, oferecendo mais alimentos industrializados do que os "in natura". Dois sujeitos $(18,1 \%)$ apontaram que a merenda contribui para o aumento do ganho ponderal e que deveria ser mais nutritivo. Assim, a merenda escolar quando monótona e desbalanceada contribui para a formação de hábitos alimentares errôneos e inadequados (SIVA, 2009). O cardápio deve, então, contemplar frutas, vegetais, pães e biscoitos integrais, reduzindo os alimentos industrializados e os de baixo valor nutritivo (SILVA, 2009).

Quanto à aceitação da merenda, 90,9\% dos sujeitos $(\mathrm{N}=10)$ observaram que nem sempre a mesma agrada aos alunos. A maioria não gosta, dependendo muito do cardápio do dia para aceitarem. Apontaram, ainda, que o lanche escolar atrapalha os alunos a almoçarem, e que o lanche deveria fazer juízo ao seu nome. As merendeiras afirmaram que há alimentos que não preparam por saberem que irá sobrar. O cardápio elaborado deveria ser elaborado para fornecer refeições saborosas e adequadas, de forma a atender as necessidades nutricionais (FLÁVIO; BARCELOS; LIMA, 2004). 
Outra questão ressaltada por Silva (2009), é que ao se pensar em elaborar uma merenda adequada deve-se programá-la mais como um lanche do que como uma refeição.

Interessante notar que durante a realização da pesquisa observou-se uma boa aceitação do lanche por parte da maioria dos alunos, verificando uma resistência maior de consumo do almoço dos alunos de tempo integral em um dia que seria ofertado carne enlatada.

Em relação a qual seria o objetivo do lanche escolar, a maioria $(\mathrm{N}=8 ; 72,7 \%)$ afirmou que seria a de suprir as carências nutricionais do aluno, a de sustentar e nutrir. Além de apontarem o objetivo de melhorar o aprendizado escolar, complementado a alimentação dos estudantes. Sabe-se que o Programa Nacional de Alimentação Escolar objetiva exatamente a suplementar a alimentação do aluno, além de melhorar suas condições nutricionais e sua capacidade de aprendizagem e auxiliar na formação de hábitos alimentares (STURION et. al., 2005).

Por fim, foi perguntado sobre a importância da merenda no cotidiano dos professores, funcionários e alunos. A grande maioria ( $N=7 ; 63,6 \%)$ respondeu ser importante somente para o aluno. E que é fundamental para estes, pois há muitos alunos que não têm uma alimentação adequada em casa.

Em uma das falas de um dos sujeitos obteve-se a seguinte afirmação:

"O lanche é para os alunos, nunca ouvir falar que os professores têm que comê-lo. A merenda é para os alunos."

Verifica-se que os cardápios ainda são falhos quanto à qualidade nutricional. No ano de 1993, o Programa de Alimentação também possuía problemas como a inadequação de cardápios quanto à qualidade nutricional, percebe-se, assim, que tal fato ainda persiste (STURION et. al., 2005). A maioria dos alimentos que formam o cardápio são industrializados. Outro problema apontado foi a repetição do cardápio. Este fato contribui para que a aceitação alimentar reduza, além de não auxiliar no combate as carências nutricionais. Um dos principais fatores para se determinar a qualidade do serviço de alimentação escolar prestado é se verificar a aceitação do alimento (FLÁVIO; BARCELOS; LIMA, 2004).

Nota-se, ainda, que os sujeitos sabem da importância e do objetivo do lanche escolar, porém não o consomem, imaginando ser necessário somente para o aluno. Muitos não acreditam servir de modelo para os alunos, principalmente para os mais novos, ignorando a importância de incentivarem e consumirem a merenda com os mesmos. Professores e funcionários são modelos para os alunos, devendo evitar consumir alimentos de baixo valor nutricional, pois têm papel essencial na formação de hábitos saudáveis (SILVA, 2009; BIZZO; LEDER, 2005). 


\subsection{ALIMENTAÇÃO SAUDÁVEL E CONSUMO DE FRUTAS E VERDURAS}

Este tópico objetivou verificar a concepção dos sujeitos acerca da alimentação saudável nos âmbitos da vida e da escola. Assim como demonstrar se estas concepções se coadunam com suas práticas pessoais.

Ao serem questionados sobre o que consideram como sendo uma alimentação saudável, um dos sujeitos $(9,09 \%)$ ressaltou que é uma alimentação que contempla alimentos dos diversos grupos alimentares e todos citaram $(\mathrm{N}=11 ; 100 \%)$, ainda, que seria uma alimentação balanceada, variada, composta por alimentos frescos e naturais, com baixo teor de gordura e com bastante consumo de fibras.

Ao se perguntar se a escola oferecia uma alimentação saudável, a grande maioria ( $\mathrm{N}=10 ; 90,9 \%)$ afirmou que às vezes o cardápio possuía esta característica, porém na maioria das vezes os alimentos que eram mandados para compor o lanche escolar eram industrializados. Segundo a Lei $n^{0}$ 11.947, o emprego da alimentação saudável e adequada, compreende o uso de alimentos variados, seguros, que respeitem a cultura, as tradições e os hábitos alimentares saudáveis, além de incentivar a aquisição de gêneros alimentícios diversificados produzidos, preferencialmente, pela agricultura familiar.

Abordando-se o local em que deveria ser aprendido sobre o que é alimentação saudável e quem deveria ensinar esta temática, todos apontaram que seria na escola e em casa. Além destes locais três sujeitos $(27,2 \%)$ também citaram como fonte de informações os programas de televisão e a internet. Quanto à figura de quem deveria ensinar, ressaltaram o papel da família, dos professores e dos profissionais da área. De acordo com Silva (2009), o âmbito escolar é ideal, exercendo grande influência na formação dos hábitos e no consumo alimentar das crianças, sendo, assim, é o local adequado para se estimular o consumo de alimentos saudáveis através da implementação de programas, projetos voltados à educação para a saúde, enfatizando-se aspectos alimentares e nutricionais. A família também é responsável por transmitir a cultura alimentar, aprendendo a criança, através dela, a respeito da sensação de fome, saciedade, desenvolvendo percepção para os sabores, suas preferências, enfim, inicia-se no seio familiar a formação do seu comportamento alimentar (SILVA, 2009). Assim, o comportamento alimentar da criança é determinado em primeiro lugar pela família e em segunda instância através de outras interações psicossociais e culturais. E em termos psicossociais, o padrão alimentar envolve os pais como educadores, sobretudo possui grande influência a atitude adotada por estes na hora da refeição (RAMOS; STEIN, 2000).

Questionando-se acerca da importância do consumo de frutas e verduras todos $(\mathrm{N}=11 ; 100 \%)$ disseram ser fundamental para se ter uma vida saudável, pois frutas e verduras melhoram o desempenho orgânico, dá vitalidade e energia, além de suprir vitaminas. Muitas evidências epidemiológicas têm recomendado para que a população aumente o consumo de frutas e verduras como forma de prevenção, reduzindo-se os riscos de diversas doenças degenerativas (ANGELIS, 2001). O consumo de frutas e verduras se insere na proposta de uma alimentação saudável que tem impacto na prevenção de diversas doenças e na promoção da saúde (SICHIERI et. al., 2000). 
Perguntou-se, ainda, se havia a presença de frutas e verduras no cardápio. A maioria $(\mathrm{N}=8 ; 72,7 \%)$ ressaltou que eram poucas as vezes que o cardápio contemplava tais alimentos, cerca de uma vez por mês, além de apontarem que quando estão presentes, sempre ou é maçã ou é banana. Tendo-se como ponto de vista da Segurança alimentar, a merenda escolar deve contemplar alimentos que atendam ao cardápio pré-estabelecido tanto em quantidade quanto em qualidade, sendo que, quanto à qualidade, os alimentos devem possuir certas características como valor nutricional adequado (PEDRAZA; ANDRADE, 2006). A monotonia alimentar pode levar a maiores riscos de deficiências nutricionais (VIERA et. al., 2002).

Em relação ao consumo de frutas e verduras, questionou-se se há este consumo por parte dos alunos e funcionários. Quanto aos alunos a maioria $(\mathrm{N}=8$; $72,7 \%$ ) dos sujeitos respondeu que este consumo se verifica às vezes e que por parte dos funcionários é mais freqüente. A respeito da freqüência de seu próprio consumo de frutas, a maioria $(\mathrm{N}=5 ; 45,4 \%)$ disse consumi-las pelo menos uma vez por dia, três $(27,2 \%)$ disseram consumi-las de 2 a 3 vezes ao dia, um sujeito apontou consumi-las menos de 3 vezes por semana, um sujeito disse consumi-las de 3 a 5 vezes ao dia e um sujeito disse consumi-las mais de 3 vezes ao dia. Em relação à freqüência de consumo de verduras, a maioria ( $\mathrm{N}=9 ; 81,8 \%)$ também afirmou consumi-las uma vez por dia e somente dois sujeitos $(18,1 \%)$ apontaram consumi-los 2 vezes ao dia. Quando foram indagados se consideravam esta freqüência adequada 6 sujeitos afirmaram que não, apontando como grande empecilho a disponibilidade na hora de comer e os "velhos hábitos", assim como a dificuldade de gostarem de alguns tipos de verduras e frutas. A Pesquisa de Orçamento Familiar, realizada em 2002-2003, demonstrou certas características negativas quanto à alimentação do brasileiro, sendo caracterizada por um consumo excessivo de açúcar e a presença insuficiente de frutas e verduras na dieta (LEVY-COSTA et. al., 2005). A Organização Mundial de Saúde recomenda um consumo mínimo de $400 \mathrm{~g}$ por dia de frutas e verduras, sendo estes alimentos muito importantes, pois além de contribuírem para o balanço energético adequado da dieta, fornecem nutrientes essenciais para a saúde do indivíduo (BARRETO et.al., 2005). Interessante apontar, ainda, que a formação do hábito alimentar se relaciona, também, com a forma como as compras de alimentos são realizadas pela família, dificilmente uma criança gostará de frutas e verduras se em sua casa não são ofertados estes alimentos ou são escassos (SILVA, 2009).

Acerca da visão sobre a alimentação do aluno em casa, muitos ( $N=9 ; 81,8 \%)$ acham que há uma dificuldade de consumir uma alimentação variada por falta de condições da família, outros $(\mathrm{N}=3 ; 27,2 \%)$ apontaram que os pais também não passam bons hábitos alimentares para seus filhos e que seria precária a alimentação. Sabe-se que o Programa Nacional de Alimentação do Escolar representa uma dimensão também social, uma vez que diante da pobreza de diversas famílias, muitas crianças recebem como única refeição do dia a merenda escolar (FLÁVIO; BARCELOS; LIMA, 2004).

Sendo assim, observa-se que a maioria dos sujeitos possuem a noção do que seria uma alimentação saudável, porém muitos não a praticam. A escola, local onde deveria, também, ensinar e cultivar estes hábitos saudáveis, apresenta cardápios que 
nem sempre contribuem para que o indivíduo pratique esta alimentação. Todos concordam que a alimentação saudável é fundamental, porém observa-se um consumo de frutas e verduras ainda incipiente.

\subsection{EDUCAÇÃO NUTRICIONAL}

Este tópico teve como objetivo demonstrar as idéias e conhecimentos dos atores escolares acerca da educação nutricional, assim como identificar as possíveis dificuldades e facilidades encontradas pela escola na elaboração e implementação de projetos nesta área.

Ao serem questionados sobre o que entendiam ser a educação nutricional, a maioria $(\mathrm{N}=7 ; 63,6 \%)$ relacionou sua definição como sendo a promoção de uma alimentação balanceada, saudável. No entanto, também houve outras respostas, que agora ressaltamos: "seria o costume; seria o modo como conscientizamos os indivíduos a comerem bem, sem exageros, comendo nutrientes necessários ao bom funcionamento do organismo e a prevenção de doenças; seria orientação e procedimento de provocar a reflexão sobre as necessidades humanas em torno da alimentação."

A educação nutricional refere-se ao ensino de bons hábitos alimentares para a população, diz respeito, assim, a um processo de aprendizagem. Busca-se a integração e harmonização de diversos níveis do indivíduo como o físico, o emocional e o intelectual. Deve-se repercutir em mudanças nos hábitos alimentares dos indivíduos e de suas famílias (FERREIRA; MAGALHÃES, 2007). A educação nutricional deve apresentar aspectos preventistas e promocionistas. A educação nutricional tem, também, o papel de produzir informações que levem os indivíduos a serem capazes de realizarem a tomada de decisão, ampliando o seu poder de escolha racional e sua responsabilização (SANTOS, 2005).

Ao ser abordada a questão se a escola possuía ou já havia realizado algum projeto sobre a importância da alimentação, a maioria $(\mathrm{N}=7 ; 63,6 \%)$ respondeu negativamente. O maior motivo alegado foi a falta de tempo e de espaço no cronograma. Os que responderam positivamente $(N=4 ; 36,3 \%)$ ressaltaram que foram trabalhados alguns temas em sala de aula, principalmente com as séries iniciais. Este fato é considerado negativo, pois a infância representa o período pelo qual está sendo fixado as bases comportamentais, inclusive relativos a alimentação. A intervenção precoce de formação através de ações educativas pode influenciar de maneira positiva na formação dos hábitos alimentares (DAVANÇO; TADDEI; GAGLIANONE, 2004).

Ao se questionar qual, então, seria a dificuldade encontrada para se trabalhar em sala, de forma continuada o tema educação nutricional, foram salientados aspectos como a falta de apoio da família do aluno $(\mathrm{N}=2 ; 18,1 \%)$, falta de tempo $(\mathrm{N}=5$; $45,4 \%)$ inclusive alegaram impedimento decorrente do conteúdo tradicional que deve ser trabalhado, de espaço $(\mathrm{N}=4 ; 36,3 \%)$ e de profissionais da área $(\mathrm{N}=2 ; 18,1 \%)$.

Acerca da experiência de terem abordado e trabalhado esta temática em sala, poucos $(\mathrm{N}=4 ; 36,3 \%)$ disseram já a ter trabalhado, encontrando uma grande dificuldade na sensibilização e na sistematização deste conteúdo. 
Interessante apontar que a participação de profissionais da área de nutrição deve se verificar de forma efetiva em conjunto com professores, pois sabe-se que definições corretas a respeito de nutrição devem ser a base para um correto desenvolvimento de ações educativas no ambiente escolar. Pressupõe que professores motivados e informados podem se tornar verdadeiros agentes transformadores do comportamento de crianças, sendo responsáveis por construir conhecimentos, atuando como modelos de comportamento a serem adotados pelas mesmas (DAVANÇO; TADDEI; GAGLIANONE, 2004). O treinamento de professores é essencial, sendo uma condição para que se proceda a sua sensibilização quanto a este conteúdo (BIZZO; LEDER, 2005).

\subsection{INFORMAÇÕES OBTIDAS NO NÚCLEO DE ASSISTÊNCIA DO EDUCANDO}

Em pesquisa realizada com Servidores do Núcleo de Assistência do Educando (NAE) de Taguatinga obteve-se os seguintes dados sobre a gestão e o funcionamento da Merenda Escolar no DF :

O Programa de Alimentação Escolar (PNAE) do Distrito Federal é gerido pela Subsecretaria de Desenvolvimento do Sistema de Ensino/Diretoria de Assistência Escolar/Gerência de Merenda Escolar em conjunto com os Núcleos de Apoio Escolar de cada Diretoria Regional de Ensino.

$>$ O papel do NAE é supervisionar a execução do PNAE, elaborar o plano de distribuição de gêneros alimentícios, verificar a aceitação dos alimentos do cardápio, distribuição dos cardápios para as escolas, entre outros.

> Os alimentos são distribuídos as escolas, seguindo-se os cardápios elaborados pelas nutricionistas, mensalmente.

> Um dos problemas verificados é a dificuldade de logística na compra e distribuição de alguns gêneros alimentícios para algumas escolas, prejudicando a consecução integral do cardápio, tendo-se que adaptálo, nestes casos.

> Há uma preocupação em se utilizar alimentos provindos da agricultura familiar; Há escolas que possuem hortas e que a utilizam de forma complementar ao cardápio da merenda escolar.

$>$ O NAE possui orientador que visita as escolas, atuando na supervisão e direcionamento das merendeiras quanto a procedimentos de armazenamento e produção.

O NAE orienta os professores a consumirem o lanche escolar como forma de estimular os alunos a também consumirem, desde que seja em sala ou no refeitório. 
$>$ Há um curso de capacitação das merendeiras na área de manipulação dos alimentos, que é realizado pelo menos uma vez por ano.

> As escolas que possuem crianças com intolerância à lactose, diabetes e doença celíaca recebem cardápios diferenciados.

$>$ Os cardápios PNAE/DF são planejados de acordo com as faixas etárias e com o cuidado de prevenir as várias doenças ocasionadas pela ingestão elevada de açúcares, sal e gorduras, buscando-se a per capita adequada, inserção de frutas e verduras, redução significativa de alimentos industrializados, entre outros.

Verifica-se que os diversos pontos acima expostos estão em consonância com as legislações e resoluções sobre o PNAE. No entanto, o fato de o cardápio as vezes não ser fielmente executado contraria o Art. 13 da Lei no 11.947, de 16 de junho de 2009, que afirma: "a aquisição de gêneros alimentícios, no âmbito do PNAE, deverá obedecer ao cardápio planejado pelo nutricionista e será realizada, sempre que possível, no mesmo ente federativo em que se localizam as escolas, observando as diretrizes de que trata o art. $2^{\circ}$ desta Lei."

\section{CONCLUSÃO}

O presente trabalho possibilitou conhecer as opiniões, as atitudes, assim como as representações dos atores escolares envolvidos sobre a alimentação e sobre a educação nutricional. Diante do exposto, podemos observar que o ambiente escolar ainda está aquém do ideal preconizado pelo conceito de Escola Promotora de Saúde, permanecendo os setores educação e saúde afastados um do outro.

Verificamos que apesar dos sujeitos possuírem informações e conhecimentos sobre a importância e o objetivo da alimentação saudável e do lanche escolar, não acreditam que sejam modelos para os alunos e não aliam a teoria que possuem à sua prática de vida diária. A idéia que fazem acerca da educação nutricional ainda é incipiente, faltando informações mais profundas sobre a temática.

Identificamos, também, que um dos maiores dificultadores para a elaboração e implementação de projetos na área de educação nutricional e sua efetiva incorporação no currículo escolar é a falta de tempo no cronograma da escola e de se não inserir tal projeto em seu plano pedagógico.

Além disto, notamos que os cardápios ainda possuem falhas quanto a sua composição e sua execução. No entanto, a legislação tem dado passos largos em direção a sua modificação, enfatizando o melhoramento de sua qualidade através da redução da oferta de alimentos industrializados e o aumento da inclusão de alimentos "in natura", provindos principalmente da agricultura familiar.

Cabe ressaltar neste contexto o papel essencial e importante do profissional nutricionista. Através da Resolução CD/FNDE nº 38, de 16 de julho de 2009, ampliouse as atribuições do nutricionista responsável técnico pelo PNAE. Além de se preocupar com a elaboração do cardápio da alimentação escolar de acordo com a 
cultura alimentar, o perfil epidemiológico da população atendida e a vocação agrícola da região, deverá ainda: coordenar o diagnóstico e o monitoramento do estado nutricional dos estudantes, deverá, ainda, acompanhar desde a aquisição dos gêneros alimentícios até a produção e distribuição da alimentação, bem como propor e realizar ações de educação alimentar e nutricional nas escolas.

É importante contextualizar as práticas de promoção da saúde a realidade deste grupo social. A constituição de grupos de trabalhos multidisciplinares, envolvendo profissionais de saúde, profissionais de educação e a comunidade pode facilitar a efetivação da proposta da Escola Promotora da Saúde e ser um real aliado para concretização dos princípios do Sistema de Saúde.

\section{REFERÊNCIA BIBLIOGRÁFICA}

ANGELIS, R. C. Novos Conceitos em Nutrição. Reflexões a respeito do elo dieta e saúde. Arquivo de Gastroenterologia, v. 38, nº 4, outubro/dezembro, 2001.

BARRETO, S. M. et. al. Análise da estratégia global para alimentação, atividade física e saúde, da Organização Mundial da Saúde. Epidemiologia e Serviços de Saúde, v.14, n. ${ }^{0} 1$, p.41-68, março, 2005.

BIZZO, M. L. G; LEDER, L. Educação nutricional nos parâmetros curriculares nacionais para o ensino fundamental. Revista de Nutrição, v. 18, no 5, p. 661-667, Campinas, setembro/outubro, 2005.

BOOG, M. C. F. Educação nutricional em serviços públicos de saúde. Caderno de Saúde Pública, v. 15, nº 2, p. 139-147, Rio de Janeiro, 1999.

BRASIL. SECRETARIA DE EDUCAÇÃO FUNDAMENTAL. Parâmetros Curriculares Nacionais: introdução aos parâmetros curriculares nacionais/ Secretaria de Educação Fundamental. Brasília: MEC/SEF, 1997.

CAMARGO, R. B.; ROVINA, E. M.; NOGUEIRA, P. C. Avaliação da Aceitação do Novo Cardápio Escolar por Alunos e Professores em uma Escola do Município de Piracicaba. Disponível em: <http://www.unimep.br/phpg/mostraacademica/anais/4mostra/pdfs/534.pdf > Acessado em: 30 de julho de 2009.

DAVANÇO, G. M.; TADDEI, J. A. A. C.; GAGLIANONE, C. P. Conhecimentos, atitudes e práticas de professores de ciclo básico, expostos e não expostos a Curso de Educação Nutricional. Revista de Nutrição, v. 17, n² 2, p. 177-184, Campinas, abril/junho, 2004.

FAGIOLI, D.; NASSER, L. A. Educação Nutricional na Infância e na Adolescência: planejamento, intervenção, avaliação e dinâmicas. São Paulo: RCN Editora, 2006.

FERREIRA, V. A.; MAGALHÃES, R. Nutrição e Promoção da Saúde: perspectivas atuais. Caderno de Saúde Pública, v. 23, nº 7, p. 1674-1681, julho, 2007. 
FLÁVIO, E. F.; BARCELOS, M. F. P.; LIMA, A. L. Avaliação Química e Aceitação da Merenda Escolar de uma Escola Estadual de Lavras-MG. Ciência e Agrotecnologia, v. 28, vo 4, p. 840-847, Lavras, julho/agosto, 2004.

FUNDO NACIONAL DE DESENVOLVIMENTO DA EDUCAÇÃO/MINISTÉRIO DA EDUCAÇÃO. Alimentação Escolar. Disponível em: <http://www.fnde.gov.br/home/index.jsp?arquivo=alimentacao_escolar.html>. Acessado em: 21 de julho de 2009.

FUNDO NACIONAL DE DESENVOLVIMENTO DA EDUCAÇÃO/ MINISTÉRIO DA EDUCAÇÃO. Lei $n^{\circ} 11.947$, de 16 de junho de 2009. Disponível em: <ftp://ftp.fnde.gov.br/web/pdde/lei_11947_16062009.pdf>. Acessado em: 20 de julho de 2009.

FUNDO NACIONAL DE DESENVOLVIMENTO DA EDUCAÇÃO/MINISTÉRIO DA EDUCAÇÃO. Resolução CD/FNDE/no 38 de julho de 2009. Disponível em: <ftp://ftp.fnde.gov.br/web/pdde/lei_11947_16062009.pdf $>$. Acessado em: 03 de agosto de 2009.

FRIZON, J. D. Hábitos Alimentares e Qualidade de Vida: Uma Discussão sobre a Alimentação Escolar. I Simpósio Nacional de Educação, UNIOESTE, Cascavel, novembro de 2008.

GONÇALVES et. al. A promoção da saúde na educação infantil. Interface Comunicação, Saúde, Educação, v. 12, nº 24, p. 181-192, janeiro/março, 2008.

GOVERNO DO DISTRITO FEDERAL. Taguatinga. Disponível em: <http://www.taguatinga.df.gov.br>. Acessado em: 28 de julho de 2009.

GUIMARÃES, S. E. R.; BORUCHOVITCH, E. O Estilo Motivacional do Professor e a Motivação Intrínseca dos Estudantes: Uma Perspectiva da Teoria da Autodeterminação. Psicologia, Reflexão e Crítica, v. 17, nº 2, p. 143-150, 2004.

KAC, G.; SICHIERI, R.; GIGANTE, D. P. Epidemiologia Nutricional. Rio de Janeiro: Editora Fiocruz/Atheneu, p. 351 e 450, 2007.

LEVY-COSTA, R. B. Disponibilidade domiciliar de alimentos no Brasil: distribuição e evolução (1974-2003). Revista de Saúde Pública, v. 39, nº4, p. 530-540, 2005.

OLIVEIRA, C. L.; FISBERG, M. Obesidade na Infância e Adolescência - Uma Verdadeira Epidemia. Arquivos Brasileiros de Endocrinologia e Metabolismo, v. 47, n², abril, 2003.

PEDRAZA, D. F.; ANDRADE, S. L. L. S. A alimentação escolar analisada no contexto de um programa da alimentação e nutrição. Revista Brasileira em Promoção da Saúde, v. 19, n³, p. 164-174, 2006.

PIPITONE, M. A. P. et. al. Atuação dos conselhos municipais de alimentação escolar na gestão do programa nacional de alimentação escolar. Revista de Nutrição, v. 16, $n^{\circ} 2$, p. 143-154, Campinas, abril/junho, 2003. 
RAMOS, M.; STEIN, L. M. Desenvolvimento do comportamento alimentar infantil. Jornal de Pediatria, v. 76, no 3, p. 229-237, Rio de Janeiro, 2000.

ROTENBERG, S.; DE VARGAS, S. Práticas alimentares e o cuidado da saúde: da alimentação da criança à alimentação da família. Revista Brasileira de Saúde Materno Infantil, v. 4, nº 1, p. 85-94, Recife, Janeiro/março, 2004.

SANTOS, L. A. S. Educação alimentar e nutricional no contexto da promoção de práticas alimentares saudáveis. Revista de Nutrição, v. 18, no 5, p. 681-692, Campinas, setembro/outubro, 2005.

SECRETARIA DE ESTADO DE EDUCAÇÃO DO DISTRITO FEDERAL. Merenda. Disponível em: <http://www.se.df.gov.br>. Acessado em: 27 de julho de 2009.

SICHIERI, R. et. al. Recomendações de alimentação e nutrição saudável para a população brasileira. Arquivo Brasileiro de Endocrinologia \& Metabologia, v. 44, n. ${ }^{\circ 3}$, São Paulo, Junho, 2000.

SILVA, G. C. Alimentação, Atividade Física e Qualidade de Vida dos Escolares do Município de Vinhedo/SP - Alimentação e Crescimento Saudável em Escolares. Campinas: IPES Editora, 2009.

STEFANINI, M. L. R. Merenda Escolar: História, Evolução e Contribuição no Atendimento das Necessidades Nutricionais da Criança. Tese de Doutorado, Universidade de São Paulo, USP, 1997.

STURION, G.L. et. al. Fatores condicionantes da adesão dos alunos ao Programa de Alimentação Escolar no Brasil. Revista de Nutrição, v. 18, no 2, p. 167-181, Campinas, março/abril, 2005.

VIEIRA, V. C. R. et. al. Perfil socioeconômico, nutricional e de saúde de adolescentes recém-ingressos em uma universidade pública brasileira. Revista de Nutrição, v. 15, n³, Campinas, setembro, 2002. 


\section{ANEXO I}

\section{ENTREVISTA}

Sexo:

Idade:

Tempo trabalhando nesta escola:

\section{1- Escola promotora da saúde.}

Qual o papel da escola no auxílio à formação de hábitos alimentares saudáveis?

Sua escola é promotora de saúde? Se a resposta for verdadeira, quais são as ações em vigor? Quem são os responsáveis?

\section{2- A merenda escolar e sua importância.}

Você considera que a merenda escolar oferecida nesta unidade é de qualidade? Justifique.

Em sua opinião como é a aceitação da merenda pelos alunos? Gostam? Sempre comem tudo?

Qual é o objetivo da merenda escolar?

Qual é a importância da merenda escolar no dia a dia dos professores, funcionários e alunos?

3- Alimentação saudável e Consumo de frutas e verduras.

O que você considera como uma alimentação saudável?

A escola oferece alimentação saudável?

Em que local se aprende o que é alimentação saudável? E quem deveria ensinar sobre esta temática?

Qual é a importância do consumo de frutas e verduras?

Há presença de frutas e verduras no cardápio da merenda?

Você observa consumo de frutas e verduras por parte dos alunos?

( ) $\operatorname{sim}$

( ) não

( ) às vezes 
( ) raramente

E por parte dos funcionários?

( ) $\operatorname{sim}$

( ) não

( ) às vezes

( ) raramente

Com que freqüência você consome frutas?

( ) mais de 3 vezes ao dia

( ) 2 a 3 vezes ao dia

( ) 1 vez ao dia

( ) 5 a 7 vezes por semana

( ) 3 a 5 vezes por semana

( ) menos de 3 vezes por semana

( ) raramente

E verduras?

( ) 2 vezes ao dia

( ) 1 vez ao dia

( ) 5 a 7 vezes por semana

( ) 3 a 5 vezes por semana

( ) menos de 3 vezes por semana

( ) raramente

Você considera esta a freqüência ideal? ( ) sim ( ) não Se não, qual é o maior impedimento para um adequado consumo de frutas e verduras?

Qual visão você tem acerca da alimentação dos alunos em casa?

\section{4- Educação Nutricional.}

O que você entende por educação nutricional?

A escola tem ou já fez algum projeto sobre a importância da alimentação saudável? Se sim, qual? Se não, porque seria? 
Qual é a dificuldade encontrada para se trabalhar em sala de forma continuada o tema: educação nutricional/alimentação saudável?

Qual é a sua área de atuação na escola? Você já teve a oportunidade de trabalhar este conteúdo com os alunos? Como foi esta experiência?

\section{ANEXO II}

Termo de Consentimento Livre e Esclarecido

Universidade de Brasília

Termo de Consentimento Livre e Esclarecido

(Fundamentado na resolução n $196 / 96$ do Conselho Nacional de Saúde)

Você está sendo convidado (a) a participar da pesquisa "Percepções de Sujeitos de uma escola pública de Ensino Fundamental do Distrito Federal sobre a alimentação escolar e a educação nutricional como tema curricular transversal." Sua participação deve-se ao fato de você ser coordenador (a) ou professor (a) de ensino fundamental ou merendeira da escola. Sua participação não é obrigatória. A qualquer momento você pode desistir de participar e retirar seu consentimento. Sua recusa não trará nenhum prejuízo em sua relação com o pesquisador, com a escola ou com a Universidade.

A pesquisa realizar-se-á no Período de novembro de 2009.

Justifica-se tal pesquisa devido à necessidade do cultivo de hábitos alimentares saudáveis, de preferência desde a infância, como forma de se ter qualidade de vida sendo a escola uma das responsáveis em auxiliar neste processo educativo.

O objetivo desta pesquisa é estudar o que professores, coordenadores e merendeiras pensam sobre alimentação escolar e sobre educação nutricional no ambiente escolar.

A sua participação nesta pesquisa consistirá em uma entrevista com a pesquisadora sobre:

1- Escola promotora da saúde.

2- A merenda escolar e sua importância.

3- Alimentação saudável e Consumo de frutas e verduras.

4- Educação Nutricional.

A entrevista será gravada em mp4. Será respeitado o seu tempo disponível para a entrevista, sempre optando por um horário que seja compatível com seu tempo livre. A entrevista terá em média duração de 20 minutos.

Não há riscos quanto a sua participação. As informações obtidas serão confidenciais e asseguramos o sigilo sobre sua participação, uma vez que os dados divulgados não possibilitarão sua identificação. 
Você receberá uma cópia deste termo onde consta o telefone e o endereço do pesquisador principal, podendo tirar suas dúvidas sobre a pesquisa e sua participação, agora ou a qualquer momento.

Pesquisadora: Daise Ellen de Melo Barbosa

Orientadora: Prof. Msc. Andreia Araujo Lima Torres

Faculdade de Ciências da Saúde Comitê de Ética em Pesquisa

Coordenador: Prof. Volnei Garrafa

Assistente: Thiago Rocha da Cunha

Contatos: cepfs@unb.br www.unb.br/fs/cep

Declaro que entendi os objetivos da pesquisa, a não existência de riscos na minha participação e concordo participar na referida pesquisa. Estou ciente de que participarei de uma entrevista individual que também será gravada em mp4.

Sujeito da Pesquisa

Brasília, de de 2009. 